\title{
Prediction scores do not correlate with clinically adjudicated categories of pulmonary embolism in critically ill patients
}

\author{
CM Katsios $M D^{1}$, $M$ Donadini $M D^{2}$, $M$ Meade $M D^{1,3}$, S Mehta $M D^{4}$, R Hall MD ${ }^{5}$, J Granton $M D^{4}$, J Kutsiogiannis $M D^{6}$, \\ P Dodek $M D^{7}$, D Heels-Ansdell $P h D^{3}$, L Mclntyre $M D^{8}, N$ Vlahakis $M D^{9}$, J Muscedere $M D^{10}$, J Friedrich $M D^{4}$, \\ R Fowler $M D^{4}$, Y Skrobik $M D^{11}, M$ Albert $M D^{11}, M$ Cox $M D^{12}$, J Klinger $M D^{13}$, J Nates $M D^{14}$, $A$ Bersten $M D^{15}$, \\ C Doig $\mathrm{MD}^{16}$, N Zytaruk BScN${ }^{3}, M$ Crowther $\mathrm{MD}^{1}$, DJ Cook $\mathrm{MD}^{1,3}$
}

\begin{abstract}
CM Katsios, M Donadini, M Meade, et al. Prediction scores do not correlate with clinically adjudicated categories of pulmonary embolism in critically ill patients. Can Respir J 2014;21(1):36-42.
\end{abstract}

BACKGROUND: Prediction scores for pretest probability of pulmonary embolism (PE) validated in outpatient settings are occasionally used in the intensive care unit (ICU).

OBJECTIVE: To evaluate the correlation of Geneva and Wells scores with adjudicated categories of PE in ICU patients.

METHODS: In a randomized trial of thromboprophylaxis, patients with suspected PE were adjudicated as possible, probable or definite PE. Data were then retrospectively abstracted for the Geneva Diagnostic PE score, Wells, Modified Wells and Simplified Wells Diagnostic scores. The chance-corrected agreement between adjudicated categories and each score was calculated. ANOVA was used to compare values across the three adjudicated PE categories.

RESULTS: Among 70 patients with suspected PE, agreement was poor between adjudicated categories and Geneva pretest probabilities (kappa $=0.01$ [95\% CI -0.0643 to 0.0941$]$ ) or Wells pretest probabilities (kappa $=-0.03$ [95\% CI -0.1462 to 0.0914$]$ ). Among four possible, 16 probable and 50 definite PEs, there were no significant differences in Geneva scores (possible $=4.0$, probable $=4.7$, definite $=4.5 ; \mathrm{P}=0.90$ ), Wells scores (possible $=2.8$, probable $=4.9$, definite $=4.1 ; \mathrm{P}=0.37$ ), Modified Wells (possible $=2.0$, probable $=3.4$, definite $=2.9 ; \mathrm{P}=0.34$ ) or Simplified Wells (possible $=1.8$, probable $=2.8$, definite $=2.4 ; \mathrm{P}=0.30$ ) . CONCLUSIONS: Pretest probability scores developed outside the ICU do not correlate with adjudicated PE categories in critically ill patients. Research is needed to develop prediction scores for this population.

Key Words: Intensive care unit; Prediction models; Pulmonary embolism
Les indices de prédiction ne sont pas corrélés avec les catégories cliniques d'embolie pulmonaire des patients gravement malades

HISTORIQUE : Les indices de prédiction d'embolie pulmonaire (EP) validés en consultations externes avant le test sont parfois utilisés à l'unité de soins intensifs (USI).

OBJECTIF : Évaluer la corrélation des indices de Geneva et de Wells avec des catégories d'EP attribuées aux patients de l'USI.

MÉTHODOLOGIE : Dans un essai aléatoire de thromboprophylaxie, les patients ayant une EP présumée ont été classés entre une EP possible, probable ou définitive. Les chercheurs ont ensuite rétrospectivement extrait les données pour déterminer l'indice diagnostique d'EP de Geneva et les indices diagnostiques de Wells, de Wells modifié et de Wells simplifié. Ils ont calculé le consensus corrigé en fonction du hasard entre les catégories et chaque indice. Ils ont utilisé l'analyse de variance pour comparer les valeurs entre les trois catégories d'EP.

RÉSULTATS : Chez les 70 patients ayant une EP présumée, on observait peu de consensus entre les catégories et les probabilités de Geneva avant le test (kappa $=0,01$ [95 \% IC -0,0643 à 0,0941]) ou les probabilités de Wells avant le test (kappa $=-0,03$ [95 \% IC $-0,1462$ à 0,0914]). Entre les quatre EP possibles, les 16 probables et les 50 définitives, les chercheurs n'ont remarqué aucune différence significative des indices de Geneva (possible $=$ 4,0 , probable $=4,7$, définitive $=4,5 ; \mathrm{P}=0,90$ ), des indices de Wells (possible $=2,8$, probable $=4,9$, définitive $=4,1 ; \mathrm{P}=0,37$ ), de Wells modifié (possible $=2,0$, probable $=3,4$, définitive $=2,9 ; \mathrm{P}=0,34$ ) ou de Wells simplifié (possible $=1,8$, probable $=2,8$, définitive $=2,4 ; \mathrm{P}=0,30$ ).

CONCLUSION : Les indices de probabilité avant le test élaborés à l'extérieur de l'USI ne sont pas corrélés avec les catégories d'EP des patients gravement malades. Des recherches s'imposent pour élaborer des indices de prédiction au sein de cette population.

before death $(4,5)$. Even in critically ill patients, PE remains one of the most common unsuspected autopsy findings (6).

PE is particularly difficult to diagnose in critically ill patients. Diagnosis requires a high index of clinical suspicion $(7,8)$ because critically ill patients are usually unable to communicate their symptoms due to their underlying condition, pharmacotherapy and mechanical ventilation. In addition, signs and symptoms, such as dyspnea,
Dulmonary embolism (PE) is a common complication in critical ill1 ness (1), with a mortality rate of up to $25 \%$ (2). Although PE has potentially serious consequences, it is often unrecognized in critically ill patients. Left undiagnosed, PE in critically ill patients who have impaired cardiopulmonary reserve may experience catastrophic consequences (3). In a 25-year longitudinal study, 9\% of hospital patients had PE at autopsy and, in $84 \%$ of these, the diagnosis was missed

${ }^{1}$ Department of Medicine, McMaster University, Hamilton, Ontario; ${ }^{2}$ Department of Clinical and Experimental Medicine, University of Insubria, Varese, Italy; ${ }^{3}$ Department of Clinical Epidemiology and Biostatistics, McMaster University, Hamilton; ${ }^{4}$ Interdepartmental Division of Critical Care, University of Toronto, Toronto, Ontario; ${ }^{5}$ Department of Medicine, Dalhousie University, Halifax, Nova Scotia; ${ }^{6}$ Department of Medicine, University of Alberta, Edmonton, Alberta; ${ }^{7}$ Department of Medicine, University of British Columbia, Vancouver, British Columbia; ${ }^{8}$ Department of Medicine, University of Ottawa, Ottawa, Ontario; ${ }^{9}$ Mayo Clinic, Rochester, Minnesota, USA; ${ }^{10}$ Department of Medicine, Queens's University, Kingston, Ontario; ${ }^{11}$ Department of Medicine, Universite de Montreal, Montreal, Quebec; ${ }^{12}$ Department of Critical Care, St Louis University, St Louis, Missouri; ${ }^{13}$ Department of Medicine, Brown University, Providence, Rhode Island; ${ }^{14}$ Department of Critical Care, Division of Anesthesiology and Critical Care, The University of Texas MD Anderson Cancer Center, Houston, Texas, USA;

${ }^{15}$ Department of Critical Care, Flinders University, Camperdown, New South Wales, Australia; ${ }^{16}$ Department of Medicine, University of

Calgary, Calgary, Alberta

Correspondence: Dr DJ Cook, Departments of Medicine, Clinical Epidemiology 6 Biostatistics, McMaster University,

1280 Main Street West, Room 2C11, Hamilton, Ontario L8S 4K1. Telephone 905-525-9140 ext 22900, e-mail debcook@mcmaster.ca 
tachycardia, hypoxemia and hypotension, which are suggestive of PE in nonintensive care unit (ICU) settings, are considerably more common in the ICU setting and attributable to many other factors. Tests that may be suggestive of physiological alterations compatible with PE (eg, decreased oxygen saturation, increased plasma troponin concentration) are often nonspecifically abnormal in critically ill patients.

Clinical decision rules (9-13) are used in medicine to provide pretest probabilities and guide decision making. Due to the silent nature of some PEs (14), simple, objective diagnostic scoring systems could be helpful in diagnosing PE. These prediction scores are often detailed in the chart or used in conversation with the ICU team because they are the only scores developed for PE. These scores have utility in patient populations in which they were developed and validated, in addition to other patient groups. Although these PE scores have been developed and tested in the emergency department, they have not been validated in the ICU setting. We aimed to establish whether these PE scores have discriminative power in the critically ill population. The objective of the present study was to evaluate whether two diagnostic PE scores - the Geneva and Wells scores - were useful in distinguishing critically ill patients who had possible, probable or definite PE according to clinical adjudication.

\section{METHODS}

The present preplanned study was conducted using the database from a recent international trial (Prophylaxis of Thromboembolism in Critical Care [PROTECT] ; Clinicaltrials.gov number: NCT00182143) that compared the low-molecular weight heparin (LMWH) dalteparin, and unfractionated heparin (UFH) for thromboprophyaxis in 3746 medical-surgical ICU patients (15). The study was conceived as a project under the 'PE-METRICS' program, which was designed to use the infrastructure of the PROTECT trial to understand the methodology, epidemiology and treatment of PE in critically ill patients. The PE-METRICS grant was submitted while PROTECT was enrolling patients to conduct work related to $\mathrm{PE}$ after the main publication. This was a peer-review, funded research program. Ethics approval was obtained as part of the PROTECT publication.

In PROTECT, patients were routinely screened with twice-weekly compression ultrasound for proximal leg deep vein thrombosis (DVT). However, PE detection did not involve screening. Patients who developed suspected PE were investigated and managed by the local ICU team using a predetermined diagnostic algorithm. First, these patients underwent bilateral leg ultrasound. Then, chest computed tomography pulmonary angiogram was performed in the 70 patients who did not have contraindications to this procedure. Thereafter, four members of a central adjudication committee (DC, MM, SM and RH) each independently adjudicated, using trial forms and the patient's chart, all cases of suspected PE. Adjudicators resolved disagreements by consensus. PE events were adjudicated as possible, probable or definite, and are defined in Table 1 . Definite PE was defined by a clearly positive test (such as characteristic intraluminal filling defect on chest computed tomography or high-probability ventilation-perfusion scan). Probable PE was defined by a high clinical suspicion (moderate or high pretest probability) and either a nondiagnostic test for PE or no test for PE. Possible PE was defined as low clinical suspicion (low pretest probability) and a nondiagnostic test for PE. 'No test for PE' is not part of the definition of a possible PE because the clinical concern had to be sufficient to order a test unless the patient was moribund or preterminal. 'No PE' was defined as either no test for PE or a clearly negative test for PE. A nondiagnostic test was defined as an inconclusive test for $\mathrm{PE}$ and did not include negative tests (15). In the present study, patients who had clinically suspected prevalent PE (diagnosed within $72 \mathrm{~h}$ of ICU admission) or incident PE (diagnosed $>72 \mathrm{~h}$ following ICU admission) were included.

\section{Geneva and Wells scores}

Appendix Tables 1 to 4 summarize the four scoring systems (9-13) used in the present study. The maximum Geneva score of 16 corresponds to a pretest probability of $81 \%$; a score of $\leq 4$ corresponds to a pretest

\section{TABLE 1} Definitions of pulmonary embolism (PE) adjudication categories

\begin{tabular}{|c|c|}
\hline PE category & Definition \\
\hline Possible & $\begin{array}{l}\text { Possible PE was defined as low clinical suspicion (low } \\
\text { pretest probability) and a nondiagnostic test for PE. 'No } \\
\text { test for PE' is not part of the definition of a possible PE } \\
\text { because the clinical concern had to be sufficient to order }\end{array}$ \\
\hline
\end{tabular}

Probable

Probable PE was defined by a high clinical suspicion (moderate or high pretest probability by the adjudication committee) and either a nondiagnostic test for PE or no test for PE

Definite

Definite PE was defined by a positive test (such as characteristic intraluminal filling defect on computed tomography pulmonary angiogram or high probability ventilation-perfusion scan)

PE adjudication categories used by adjudication committee defined in the Prophylaxis of Thromboembolism in Critical Care (PROTECT) Trial (15)

probability of $10.3 \%(9,11)$. The Wells PE Diagnostic score has a maximum score of 12.5 , which corresponds to a pretest probability of $40.6 \%$; a score of $\leq 4$ corresponds to a pretest probability of $<7.8 \%$ (10). The Modified Wells PE Diagnostic score (13) has a maximum score of 9 ; a score of $\leq 4$ corresponds to a pretest probability of $6 \%$ and a score of $>4$ corresponds to a pretest probability of $78 \%$. The Simplified Wells PE Diagnostic score (12) has a maximum score of 7, which corresponds to a pretest probability of $62 \%$; the minimum score of 1 corresponds to a pretest probability of $12 \%$.

\section{Pilot exercise}

A pilot exercise was conducted to examine and optimize interobserver rater agreement in preparation for the full study. In duplicate and independently, two research personnel ( $\mathrm{CK}$ and $\mathrm{MD}$ ) retrospectively abstracted data relevant to the scoring systems from medical records in a computerized ICU clinical information system (CareVue, Philips Inc, USA), written clinical notes, laboratory and other test results from the day that PE was suspected (within $12 \mathrm{~h}$ ). Using pretested forms and an implementation manual, the two blinded raters abstracted data regarding signs and symptoms of $\mathrm{PE}$, and data to calculate diagnostic score in a reliability and calibration exercise on one trial patient; subsequently, two blinded raters abstracted 18 items (six symptoms, eight signs, two tests and two scores) from the medical records of four trial patients. These individual variables were defined as per previous studies (16): six symptoms (dyspnea, pleuritic chest pain, substernal chest pain, cough, hemoptysis and syncope), eight signs (fever $>38^{\circ} \mathrm{C}$, tachypnea with respiratory rate $>30$ breaths/min, tachycardia [heart rate $>100$ beats/min], hypotension [systolic blood pressure $<100 \mathrm{mmHg}$, central cyanosis, oxygen saturation $<90 \%$, physical signs of DVT such as calf pain, unilateral calf swelling or pain on flexion, and cardiopulmonary arrest) and two test results (arterial partial pressure of oxygen and echocardiographic findings of right heart strain). Data were also abstracted to calculate the Geneva Diagnostic score and the original Wells score. Chance-corrected agreement (using the original interpretation by Fleiss [17]) was calculated between two raters' measures of each dichotomous variable and each score.

Chance-corrected agreement values on the initial pilot exercise for symptoms were: dyspnea $\kappa=0.82$, pleuritic chest pain $\kappa=0.97$, substernal chest pain $\kappa=0.90$, cough $\kappa=0.85$, syncope $\kappa=0.85$; for signs: fever $\kappa=0.71$, tachypnea $\kappa=0.78$, tachycardia $\kappa=0.60$, hypotension $\kappa=0.95$, hemoptysis $\kappa=0.85$, cyanosis $\kappa=0.59$, desaturation $\kappa=0.91$, physical signs of DVT $\kappa=0.87$, cardiopulmonary arrest $\kappa=0.88$; and for test results: arterial blood gas $\mathrm{PO}_{2} \kappa=0.70$, echocardiographic signs of right heart strain $\kappa=0.90$. For PE diagnostic scores, agreement was: Geneva diagnostic score $\kappa=0.53$, original Wells score $\kappa=0.71$ (Table 2). 
TABLE 2

Pilot study: Agreement scores

\begin{tabular}{lclc}
\hline Symptom & $\mathbf{K}$ & \multicolumn{1}{c}{ Signs } & $\mathbf{K}$ \\
\hline Dyspnea & 0.82 & Fever $>38^{\circ} \mathrm{C}$ & 0.71 \\
Pleuritic chest pain & 0.97 & Respiratory rate $>30$ breaths $/$ min & 0.78 \\
Substernal chest pain & 0.90 & Heart rate $>100$ beats $/$ min & 0.60 \\
Cough & 0.85 & Systolic blood pressure $<100 \mathrm{mmHg}$ & 0.95 \\
Syncope & 0.85 & Cyanosis & 0.59 \\
& & Desaturation $<90 \%$ & 0.91 \\
& & Physical signs of deep vein thrombosis & 0.87 \\
& & Cardiopulmonary arrest & 0.88 \\
& & Hemoptysis & 0.85 \\
Test results & $\mathbf{K}$ & Diagnostic models & $\mathbf{K}$ \\
\hline ABG $\mathrm{PO}_{2}$ criteria & 0.70 & Wells & 0.71 \\
Echo criteria & 0.90 & Geneva & 0.53 \\
\hline
\end{tabular}

Inter-rater agreement (between two raters) for signs, symptoms and test results for pulmonary embolism in five pilot study patients. Kappa values are presented, indicating chance-corrected agreement between two raters. ABG Arterial blood gas; Echo Echocardiography

Case report forms were distributed to research personnel in $67 \mathrm{cen}$ tres that participated in the PROTECT trial (15). Blinded to study drug and PE adjudication status, research personnel (physicians or research coordinators) at each centre retrospectively abstracted data to calculate four scores: the Geneva score, original Wells score, Modified Wells score and Simplified Wells score. The research personnel who abstracted the data were asked to tabulate the points for each score based on interpreting the physicians' notes, nurses' notes, laboratory or other test values. The attempt was made to make assessments and assign numerical points as per clinical practice.

\section{Analysis}

To examine the relationship among the three adjudicated categories of possible, probable and definite $\mathrm{PE}$, and each of the low, intermediate and high pretest probability categories of PE on the Geneva and Wells scores, respectively, chance-corrected agreement was calculated using kappa and its original interpretation by Fleiss (17). ANOVA was used to examine the association between clinically adjudicated categories of $\mathrm{PE}$ and values for each of the four diagnostic scores. $\mathrm{P}<0.05$ indicated that a diagnostic score was significantly different across three adjudicated categories of possible, probable and definite PE.
TABLE 4

Pretest probability scores of published prediction models (Geneva, Wells, Modified Wells and Simplified Wells score) stratified according to PROTECT pulmonary embolism adjudication category

\begin{tabular}{lcccc}
\hline \multirow{2}{*}{$\begin{array}{l}\text { Prediction } \\
\text { model }\end{array}$} & $\begin{array}{c}\text { Possible } \\
(\mathbf{n = 4})\end{array}$ & $\begin{array}{c}\text { Probable } \\
(\mathbf{n}=\mathbf{1 6})\end{array}$ & $\begin{array}{c}\text { Definite } \\
(\mathbf{n}=\mathbf{5 0})\end{array}$ & $\mathbf{P}$ \\
\hline Geneva score & $4.0 \pm 3.5$ & $4.7 \pm 2.8$ & $4.5 \pm 2.8$ & 0.90 \\
Original Wells & $2.8 \pm 1.0$ & $4.9 \pm 3.4$ & $4.1 \pm 2.8$ & 0.37 \\
Modified Wells & $2.0 \pm 0.8$ & $3.4 \pm 2.4$ & $2.9 \pm 1.9$ & 0.34 \\
Simplified Wells & $1.8 \pm 0.5$ & $2.8 \pm 1.7$ & $2.4 \pm 1.3$ & 0.30 \\
\hline
\end{tabular}

Data presented as mean $\pm S D$ unless otherwise indicated. See Appendix Tables 1 to 4 for the prediction models. PROTECT Prophylaxis of Thromboembolism in Critical Care trial

\section{RESULTS}

There were 3746 patients included in the PROTECT trial. There were 70 patients in the final study including the five pilot patients, reflecting all 70 patients who were adjudicated for PE in the PROTECT trial; these patients were cared for in 30 of the 67 participating centres (Table 3). This yields an incidence of 1.9\% (70 of 3746) of patients who were adjudicated for PE. Of the $70 \mathrm{PEs}$ in the present study, 10 were prevalent and 60 were incident. Of 70 patients, four were adjudicated as 'possible PE', 16 as 'probable PE' and 50 as 'definite PE'. Agreement was poor between adjudicated categories of PE and both Geneva score pretest probabilities ( $\kappa=0.01[95 \% \mathrm{CI}$ -0.0643 to 0.0941$])$ and Wells score pretest probabilities $(\kappa=-0.03$ [ $95 \%$ CI -0.1462 to 0.0914$]$ ). Across four patients who had possible, 16 patients who had probable and 50 patients who had definite PE, there were no significant differences in total Geneva scores (possible $=$ 4.0 , probable $=4.7$, definite $=4.5 ; \mathrm{P}=0.90$ ), total original Wells scores ( possible $=2.8$, probable $=4.9$, definite $=4.1 ; \mathrm{P}=0.37)$, Modified Wells scores (possible $=2.0$, probable $=3.4$, definite $=2.9 ; \mathrm{P}=0.34$ ) or Simplified Wells scores $($ possible $=1.8$, probable $=2.8$, definite $=2.4$; $\mathrm{P}=0.30$ ) (Table 4).

\section{DISCUSSION}

Among 70 patients with a clinical suspicion of PE adjudicated in the PROTECT trial (15), agreement was poor among adjudicated categories of PE and each of the Geneva score and three Wells scores. Across

\section{TABLE 3}

Demographic and clinical characteristics of patients adjudicated for pulmonary embolism (PE)

\begin{tabular}{|c|c|c|c|c|}
\hline Characteristic & Possible PE & Probable PE & Definite PE & $\mathbf{P}$ \\
\hline Patients, $\mathrm{n}$ & 4 & 16 & 50 & - \\
\hline \multicolumn{5}{|l|}{ Patient demographics } \\
\hline Age, years, mean \pm SD & $59.9 \pm 22.8$ & $56.7 \pm 14.7$ & $59.2 \pm 16.8$ & 0.86 \\
\hline Body mass index, $\mathrm{kg} / \mathrm{m}^{2}$, mean $\pm \mathrm{SD}$ & $22.9 \pm 4.0$ & $34.4 \pm 10.7$ & $29.8 \pm 8.5$ & 0.05 \\
\hline Medical admission, n (\%) & $4(100.0)$ & $13(81.3)$ & $40(80.0)$ & $>0.99$ \\
\hline APACHE II score, mean \pm SD & $21.0 \pm 6.1$ & $22.5 \pm 7.6$ & $21.2 \pm 5.9$ & 0.77 \\
\hline History of or current malignancy & $1(25.0)$ & $0(0.0)$ & $4(8.0)$ & 0.22 \\
\hline Heart failure & $0(0.0)$ & $0(0.0)$ & $2(4.0)$ & $>0.99$ \\
\hline Personal history of venous thromboembolism & $0(0.0)$ & $1(6.3)$ & $3(6.0)$ & $>0.99$ \\
\hline Family history of venous thromboembolism & $0(0.0)$ & $0(0.0)$ & $0(0.0)$ & - \\
\hline End-stage renal disease (dialysis dependent) & $0(0.0)$ & $0(0.0)$ & $0(0.0)$ & - \\
\hline Prevalent $\mathrm{PE}^{*}$ & $1(25.0)$ & $0(0.0)$ & $10(20.0)$ & 0.10 \\
\hline
\end{tabular}

${ }^{*}$ Diagnosed before intensive care unit admission. APACHE Acute Physiology and Chronic Health Evaluation 
the three adjudicated categories of PE, there were no significant differences in total Geneva scores, Wells scores, Modified Wells scores or Simplified Wells scores. We conclude that many physiological variables used in these models, shown to be valuable in the ambulatory setting, are of questionable utility when applied to intubated, critically ill patients.

Two possible explanations for the poor agreement among adjudicated categories and prediction scores relate to the population we studied and the quality of information in the medical charts. Regarding the first explanation, some of the variables required to calculate these scores cannot be discerned in critically ill patients (eg, dyspnea) and are, therefore, nondiscriminatory. All patients in PROTECT were considered to be 'at risk for' DVT and PE. It is possible that the incidence of venous thromboembolism in this trial could be decreased as a consequence of universal prophylaxis with either UFH or LMWH. Furthermore, it is possible that patients receiving thromboprophylaxis may have different signs and symptoms of PE than patients not receiving prophylaxis, although, to our knowledge, this has not been studied. Bahia and Albert (13) demonstrated that these clinical scores accurately predict $\mathrm{PE}$ in prophylaxed hospitalized patients. There have been no studies in the literature that document the utility of these scores in thromboprophylaxed critically ill patients.

Regarding the issue of information quality, the original data for this substudy, and the original trial data collected by research coordinators on which the adjudication was based, were from patient medical records, which are known in both in paper and electronic formats to contain errors of over- (18) and under- (19) documentation on the part of nurses $(20)$, trainees $(21,22)$ and staff physicians $(23)$. In other words, some components of the scoring systems may be too challenging to detect in ICU patients, whereas other predictor variables may be present or absent, but the information may not be recorded in the medical charts.

Strengths of the present study include the development, testing and refinement of data abstraction tools in a pilot exercise that documented excellent inter-rater reliability before starting the full study. To avoid ascertainment bias, data for the scoring systems were abstracted blinded to study drug, participating centre and adjudicated outcome. Similarly, the original PE events were adjudicated in quadruplicate, blinded to study drug, participating centre and other adjudicator assessments. Given the lack of previous evidence to evaluate well-known scoring systems for the diagnosis of PE in critically ill patients, we designed the present study a priori to examine the utility of these diagnostic scores in the ICU setting.

Limitations to the present study include the relatively small number of patients with PE. Because this thromboprophylaxis trial did not protocolize screening for $\mathrm{PE}$, as per usual practice, not all patients underwent the same testing to diagnose PE (15). We did not compare scores in patients with suspected $\mathrm{PE}$, but were subsequently proven not to have PE based on objective testing, or patients with no suspicion whatsoever of PE, thereby replicating practice. However, silent PE may be relatively common, as suggested in a recent study involving 176 medical-surgical ventilated ICU patients requiring thoracic computed tomography. In this cohort, 33 (18.7\%) had PE, including $20(61 \%)$ with no clinical suspicion (24). Unlike some patients studied in the original prediction score studies, ICU patients in the present study were all receiving either UFH or LMWH thromboprophylaxis and had poor cardiopulmonary reserve, which may have influenced the threshold of concerns when various signs or symptoms were found. The original prediction score studies were also not necessarily completed in thromboprophylaxed patients; however, they have been found to be discriminatory in this population (13).

Our findings may not be generalizable to all types of critically ill patients (eg, trauma, neurosurgery or cardiac surgery, who were not enrolled in the present study).

We did not apply the prediction scores to all patients, including those in whom PE was never considered as a clinical problem, as per the original score development process. We chose our methods to best approximate the use of the prediction scores in some critical care practices, abstracting data for these scores in patients in whom the clinical suspicion of PE existed.

Developing PE scoring systems in the future would ideally incorporate other tests such as troponin, B-type natriuretic peptide values or echocardiographic findings. Specifically, elevated troponin levels predict short-term mortality as shown in a meta-analysis of 20 studies in general hospitalized patients with acute PE and normal blood pressure (OR 5.24 [95\% CI 3.28 to 8.38]) (25). Another meta-analysis demonstrated higher risk of death associated with specific echocardiographic findings (OR 2.4 [95\% CI 1.3 to 4.3[) and elevated B-type natriuretic peptide (OR 7.7 [95\% CI 2.9 to 20]) in patients with hemodynamically stable PE (26).

\section{CONCLUSION}

Pretest probability models developed and validated outside the ICU setting do not correlate with clinically suspected PE in the ICU. Further clinical research is needed to identify features that help to reliably identify patients with PE in this setting, and to develop a practical clinical prediction rule for critically ill patients with suspected PE. Ideally, the latter would incorporate a complete spectrum of risk using readily available clinical, physiological and laboratory tests. Such new prediction models could be of great value to supplement clinical judgment, and aid in more timely identification and appropriate treatment of PE and, possibly, improved patient outcomes.

AUTHOR CONTRIBUTIONS: DJC is the guarantor of the content of the manuscript, including the data and analysis. CK and MD constructed and piloted the case report forms. CK and DJC conceived of the study and drafted the manuscript. DJC, MM, SM and RH adjudicated the patients with PE. NZ coordinated global data collection. CY contributed to manuscript editing regarding statistical analysis. DHA conducted the statistical analysis. All authors contributed to the PROTECT trial and this substudy, and read and approved the final manuscript. The authors thank the patients and families who agreed to participate in this study, and the Research Coordinators and Site Investigators in all participating centres (see list). The authors thank Chenglin Ye for helpful comments on earlier drafts of this manuscript and the anonymous peer reviewers for their assistance and suggestions reviewing earlier iterations.

FUNDING: This study was funded by the Canadian Institutes for Health Research, the Heart and Stroke Foundation of Canada, the Australian and New Zealand College of Anesthetists Research Foundation and Physicians Services Incorporated. R Fowler is a Clinician Scientist of the Heart and Stroke Foundation. M Crowther holds a Career Investigator Award from the Heart and Stroke Foundation of Ontario and the Leo Pharma Chair in Thromboembolism Research at McMaster University and St Joseph's Healthcare, Hamilton. Dr Cook is a Research Chair of the Canadian Institutes of Health Research. Dr Crowther sat on advisory boards for Leo Pharma, Pfizer, Bayer, Boehringer Ingelheim, Alexion, CSL Behring and Artisan Pharma, and received funding for a presentation from Leo Pharma. Dr Crowther's institution has received funding for research projects from Boehringer Ingelheim, Octapharm, Pfizer and Leo Pharma. There are no financial/nonfinancial disclosures or conflicts of interest for any of the other authors.

\section{PROTECT PARTICIPATING CENTRES}

\section{Canadian Investigators}

- Dr Deborah Cook (Lead), Ellen McDonald, Andrea Tkaczyk, France Clarke; Pharmacist Christine Wallace; St Joseph's Healthcare, Hamilton, Ontario

- Drs Rick Hall and Graeme Rocker, Lisa Julien, Debbie Wright, Caroline Roy, Judy Theriault, Susan Pleasance; Pharmacy Technicians Debi Snow and Shannon Herbert; Capital Health Queen Elizabeth II Health Science Center, Halifax, Nova Scotia

- Dr Maureen Meade, Lori Hand; Pharmacy Technician Maya Biljan; Hamilton Health Sciences, Hamilton General Hospital, Hamilton, Ontario 
- Dr Andreas Freitag, Christine Wynne, Mark Duffett, Michelle Kho, Nicole Zytaruk; Pharmacy Technician Karen Currie; Hamilton Health Sciences, McMaster Hospital, Hamilton, Ontario

- Dr John Granton, Andrea Matte, Paulina Farias, Leslie Chu, Nancy Brockest, Stephanie Go, Margaret McGrath-Chong, Madison Dennis, Marc Lipkus, Emily Stern, Ryan Albert; Pharmacy Ron Seto, Muhammad Zuberi, Jie Ming and Laura Arus-Pampin, Muhammad Walid, Robert Solek, Kim De Freitas; University Health Network, Toronto General Hospital, Toronto, Ontario

- Drs Stephan Langevin, Francois Lauzier and Alexis F Turgeon, Martine Blais, Maxime Beauparlant, Julie Asselin, Caroline Roy, Chantal Gagne, Marie Thibodeau; Pharmacists Anik Rioux, Tuong-Vi Tran; Hôpital de l'Enfant-Jésus, Quebec City, Quebec

- Dr Germain Poirier, Isabelle Neas, Sandrine Spearson; Pharmacist Betty Ton; Charles LeMoyne Hospital, Montreal, Quebec

- Drs Lauralyn McIntyre and Paul Hébert, Irene Watpool, Tracy McArdle, Claude Gaudert, Paule Marchand, Carson Davidson; Pharmacists Anne-Marie Dugal and Susan Fetzer; Ottawa Hospital, General Campus, Ottawa, Ontario

- Dr Joe Pagliarello, Mary-Jo Lewis, Erin Murphy, Julia Foxall; Pharmacist Sherry Weir; Ottawa Hospital Civic Campus, Ottawa, Ontario

- Dr Yoanna Skrobik, Johanne Harvey, Stefania Chitu; Pharmacists Marceline Quach and Linda Pinet; Maisonneuve Rosemont Hospital, Montreal, Quebec

- Dr Martin Albert, Carole Sirois, Carole Nadon, Stephanie Dolle, Audrey-Anne Gosselin, Patrice Deroy; Pharmacists Anne Julie Frenette and David Williamson; Hôpital du Sacré-Coeur de Montréal, Montreal, Quebec

- Dr Sangeeta Mehta, Cheryl Ethier, Sam Tirgari, Lindsay Steinberg, Rod McDonald, Vidhya Sivanantham, Kristofer Bandayrel, Friederike Quittnat Pelletier, Marnie Kramer-Kile, Maedean Brown, Scott Kim; Pharmacist Holly Leung; Mount Sinai Hospital, Toronto, Ontario

- Dr Robert Fowler, Nicole Marinoff, Karen Code, Boris Bojilov, Derek Parsotam; Pharmacist John Iazzetta; Sunnybrook Hospital, Toronto, Ontario

- Dr John Marshall, Orla Smith, Beth Fry, Kerri Porretta, Yoon Lee, Jeanna Morrissey, Victoria Wen; Pharmacy Technicians Laura Parsons and Ann Kosinski; St Michael's Hospital, Toronto, Ontario

- Dr John Muscedere, Susan Fleury, Nicole Godfrey, Sharlene Hammond, Elizabeth Mann, Monica Myers, Amber Robinson; Pharmacist Chris Grey; Kingston General Hospital, Kingston, Ontario

- Drs Sean Keenan and Steven Reynolds, Miroslav Svetik, Mary Van Osch; Pharmacist Anne-Marie Liberman; Royal Columbian Hospital, Westminster, British Columbia

- Drs Dean Chittock and Vinay Dhingra, Maureen Gardner, Susan Logie, Denise Foster, Roger Autio, Dara Davies, Pia Ganz, Laurie Smith; Pharmacy: Jane Day, Kaldip Mattu and Judy Yip; Vancouver General Hospital, Vancouver, British Columbia

- Dr Peter Dodek, Betty Jean Ashley, Sheilagh Mans; Pharmacist Mara Pavan; St Paul's Hospital, Vancouver, British Columbia

- Dr Chip Doig, Linda Knox, Crystal Wilson, Kevin Champagne; Pharmacist Angela Kayall Peters; Calgary University Foothills Hospital, Calgary, Alberta

- Dr Niall Ferguson, Andrea Matte, James Stevenson, Joel Elman, Madison Dennis; Pharmacist Jenn Tung, Robert Solek, Kim De Freitas, Nga Pham; University Health Network, Toronto Western Hospital, Toronto, Ontario
- Dr Jim Kutsogiannis, Patrica Thompson, Norine Whalen; Pharmacist Liz Helboe; Royal Alexandra Hospital, Edmonton, Alberta

- Dr Francois Lellouche, Marie-Claude Ferland, Patrick Dussault, Caroline Jacob, Marie-Eve Morneau, Nancy Laberge; Pharmacist Nathalie Chateauvert; Laval Hospital, Quebec City, Quebec

- Dr Tim Karachi, Andrea Tkaczyk; Pharmacy Technician Diane Lourenco; Hamilton Health Sciences, Juravinski Hospital, Hamilton, Ontario

- Dr Michael Jacka, Marleen Irwin, Carmen Chan, Leeca Sonnema, Kelly Marsh, Jennifer Maurer, Tamara Kreidl, Candice Varden, Carey Kinjerski; Pharmacist Noelle Carey; University of Alberta, Edmonton, Alberta

- Dr Chip Doig, Linda Knox, Crystal Wilson, Kevin Champagne; Pharmacist Angela Kayall Peters; Calgary University Peter Lougheed Hospital, Calgary, Alberta

- Dr Kosar Khwaja, Laura Banici, Carole Sirois, Lena Havell; Pharmacists Gilbert Matte and Kathleen Normandin; Montreal General Hospital, Montreal, Quebec

- Dr Gordon Wood, Fiona Auld, Leslie Atkins; Pharmacist John Foster-Coull; Vancouver Island Health Authority, Vancouver, British Columbia

- Drs Olivier Lesur and Francois Lamontagne, Sandra Proulx; Pharmacist Sylvie Cloutier, Brigitte Bolduc, Marie-Pierre Rousseau, Julie Leblond; Sherbrooke University Hospital and Centre de Recherche Clinique Étienne-Le Bel, Sherbrooke, Quebec

- Dr Kosar Khwaja, Laura Banici, Carole Sirois, Lena Havell; Pharmacists Gilbert Matte and Kathleen Normandin; Royal Victoria Hospital, Montreal, Quebec

- Drs Gerald Hollinger and Vasanti Shende, Vanessa Belcastro; Pharmacist Jane Martin; Guelph General Hospital, Guelph, Ontario

- Dr Bill Plaxton, Anders Foss; Pharmacy Technicians Heather McDougall, Sharon Morris and Goran Petrovic; Grand River Hospital, Kitchener, Ontario

- Dr Bojan Paunovic, Kym Wiebe, Nicole Marten; Pharmacist Denise Sawatzky; St Boniface Hospital, Winnipeg, Manitoba

- Dr Jonathan Eisenstat, Tammy Doerle; Pharmacist Linda Skinner; Lakeridge Health, Oshawa, Ontario

- Drs Steven Reynolds and Sean Keenan, Sheilagh Mans; Pharmacist Ray Jang; Surrey Memorial Hospital, Surrey, British Columbia

- Dr Michael Sharpe, Mona Madady; Pharmacist Chandika Mankanjee; London Health Sciences Center, London, Ontario

\section{Australian Investigators}

- Drs Jamie Cooper (Lead) and Andrew Davies, Shirley Vallance, Cindy Weatherburn, Jasmin Board, Victoria Bennett; Pharmacists Anne Mak and Sook Wern Chua; Alfred Hospital, Melbourne

- Drs Simon Finfer and Naresh Ramakrishnan (deceased), Simon Bird, Julie Potter, Anne O'Connor, Susan Ankers; Pharmacist Maggie Gibson; Royal North Shore Hospital, Sydney

- Dr Jack Cade, Deborah Barge, Tania Caf, Belinda Howe; Pharmacist Emma Michael; Royal Melbourne Hospital, Melbourne

- Dr Rinaldo Bellomo, Glenn Eastwood, Leah Peck, Donna Goldsmith, Kim O'Sullivan; Lead Pharmacists Dr Michael Ching, Jean Schmidt, Mei Ho and Bailey Lim; Austin Hospital, Melbourne

- Drs David Ernest, Sam Radford, Ann Whitfield and Anthony Cross, Suzanne Eliott, Jaspreet Sidhu, Belinda Howe, Inga Mercer, Angela Hamilton (deceased); Pharmacist Paula Lee; Box Hill Hospital, Melbourne

- Dr John Botha, Jodi Vuat, Sharon Allsop, Nina Fowler; Pharmacist Chui Yap; Frankston Hospital, Frankston

- Drs Tim Crozier, Jonathan Barrett and Chris Wright, Pauline Galt, Carly Culhane, Rebecca Ioannidis, Sue Burton, Marnie Reily, 
Cyveen Weeraratna; Pharmacist Helen Kopp; Monash Medical Centre, Melbourne

- Dr Ian Seppelt, Leonie Weisbrodt, Robyn Bond; Pharmacists Stella Suen and Jason Trinh; Nepean Hospital, Sydney

- Dr David Evans, Justine Rivett, Stephanie O'Connor, Alex Poole; Pharmacist Peter Slobodian; Royal Adelaide Hospital, Adelaide

- Dr Clive Woolfe, Dorrilyn Rajbhandari, Caitlin Rees; Pharmacist Justine Hay; Royal Prince Alfred Hospital, Camperdown

- Drs John Edington and Jason Fletcher, Julie Smith, Catherine Boschert; Pharmacist Richard Summers; Bendigo Health Care, Bendigo

- Dr Graham Reece, Treena Sara, Kiran Nand; Pharmacist Rabsima Ibrahim; Blacktown Hospital, Blacktown

- Drs Andrew Bersten and Alex Gallus, Elisha Matheson, Margie O'Callaghan; Pharmacist Kelly Woolley; Flinders Medical Center, Adelaide

- Dr Neil Orford, Tania Elderkin, Melissa Fraser, Allison Bone, Tania Salerno, Anne Kinmonth; Pharmacist Paul Muir; Barwon Health, Geelong Hospital, Geelong

- Dr Subhash Arora, Bridget O'Bree, Katherine Shepherd; Pharmacists Kerry Gray and Tu Vinh; Dandenong Hospital, Dandenong

Drs Alan Davey_Quinn and Martin Sterba, Bronwyn Ruth Johnson, Renee Xu, Francisco Hill; Pharmacist Julie Thompson; Wollongong Hospital, Wollongong

- Dr Rajaram Ramadoss, Josette Wood; Pharmacist Eric Tah Wai Yap; Lyell McEwin Hospital, Adelaide

Brazilian Investigators

- Dr Marcelo Garcia da Rocha (Co-Lead), Andréa Kramer, Martha Hädrich; Pharmacist Patrícia Soares, Fernando Frosi; Santa Casa Hospital, Porto Allegre

- Drs Nilton Brandao, Cassiano Teixeira and Cíntia Roehrig, Juliana Zeni; Pharmacist Daniel Panizzi; Moinhos de Vento Hospital, Porto Alegre

- Drs Suzana Alves da Silva and Rubens Costa Filho, Renato Correa Alves Moreira and Plínio N. Gomes and Rodrigo Biondi; Pharmacist Marcia Caneca, Graziele Silva, Pró Cardíaco Hospital, PROCEP, Rio de Janeiro

- Drs Otavio Berwanger (Co-Lead) and Edson Romano, Anna Maria Buehler; Pharmacist Marcelo Murad and Paulo Buononato; Hospital Coracao Research Institute HCor, São Paulo

- Drs Helio Penna Guimarães and Renato D Lopes, Adriano Truffa, Rosana Nakamura, Lillian Mazza Barbosa; Pharmacist Rosana Suemi Nakamura; Hospital São Paulo, São Paulo

Saudi Arabian Investigators

- Dr Ismael Qushmaq (Lead), Jean Brennick, Sawsan Bassi; Pharmacist Amnah Mukhtar, Majdah Attas and Amer Soliman; King Faisal Specialist Hospital and Research Center, Jeddah

- Dr Mohammed Alsultan and Yaseen Arabi, Riette Brits; Pharmacist Antoine Cherfan; King Saud Bin Abdulaziz University for Health Sciences, Riyadh

- Dr Jamal Alhashemi, Sanaa Shalabi; Pharmacist Randa Ainosah; King Abdulaziz University Hospital, Jeddah

- Drs Yasser Mandourah and Nadeem Shaikh; Pharmacist Shatha Shosho; Riyadh Military Hospital, Riyadh

- Drs Manal Al-Hazmi and M. Ali Al-Azem, Trevor Wyngaard; Pharmacist Yahya Moustafa; King Fahad Medical City Hospital, Riyadh

United States Investigators

- Dr James Klinger, Barbara Smithson; Pharmacist Andrea Monckeberg; Rhode Island Hospital, Providence, Rhode Isalnd

- Dr Nicholas E Vlahakis (Lead), Laurie Meade; Pharmacist Debbie Bauer; Mayo Clinic, Rochester, Minnesota
- Dr Michael Cox, Jackie O'Brien, Catherine Krause; Pharmacist Sandra Ahearn; St John's Mercy Medical Center, St Louis, Missouri

- Drs Joseph Nates and Sajid Haque, Deidre Mooring, Rose Erfe, Paula Nickerson; Pharmacist KimMcConnell; University of Texas MD Anderson Cancer Center, Houston, Texas

United Kingdom Investigators

- Drs Marlies Ostermann (Lead) and David Treacher, Tony Sherry, John Smith, Barnaby Sanderson, Josephine Ng, John Brooks, Ling Lim, Katie Lei; Pharmacists Paul Tunstell and Dr Cathy McKenzie, Francesco Cicirello; King's College London, Guy's and St Thomas' Hospital, London

\section{APPENDIXES}

\section{APPENDIX TABLE 1 \\ Geneva Diagnostic score}

\begin{tabular}{|c|c|}
\hline Clinical characteristic & Point value \\
\hline Previous PE/DVT & 2 \\
\hline Heart rate $>100$ beats $/ \mathrm{min}$ & 1 \\
\hline Recent surgery & 3 \\
\hline \multicolumn{2}{|l|}{ Age, years } \\
\hline $60-79$ & 1 \\
\hline$>80$ & 2 \\
\hline \multicolumn{2}{|l|}{$\mathrm{PaCO}_{2}, \mathrm{mmHg}$} \\
\hline$<36$ & 2 \\
\hline $36-39$ & 1 \\
\hline \multicolumn{2}{|l|}{$\mathrm{PaO}_{2}, \mathrm{mmHg}$} \\
\hline$<48.7$ & 4 \\
\hline $48.7-59.9$ & 3 \\
\hline $60-71.2$ & 2 \\
\hline $71.3-83.4$ & 1 \\
\hline Plate-like atelectasis on chest radiograph & 1 \\
\hline Elevated hemidiaphragm on chest radiograph & 1 \\
\hline \multicolumn{2}{|c|}{$\begin{array}{l}\text { DVT Deep vein thrombosis; } \mathrm{PaCO}_{2} \text { Partial pressure of carbon dixide; } \mathrm{PaO} \\
\text { Partial pressure of oxygen; } \mathrm{PE} \text { Pulmonary embolism }\end{array}$} \\
\hline \multicolumn{2}{|l|}{$\begin{array}{l}\text { APPENDIX TABLE } 2 \\
\text { Original Wells score }\end{array}$} \\
\hline Clinical characteristics & Point value \\
\hline Clinical signs of DVT & 3 \\
\hline Heart rate $>100$ beats $/ \mathrm{min}$ & 1.5 \\
\hline Recent surgery/immobilization & 1.5 \\
\hline Previous PE/DVT & 1.5 \\
\hline Hemoptysis & 1 \\
\hline Active cancer & 1 \\
\hline Alternative diagnosis less likely & 3 \\
\hline
\end{tabular}

DVT Deep vein thrombosis; PE Pulmonary embolism

\section{APPENDIX TABLE 3}

\section{Simplified Wells score}

\begin{tabular}{lc}
\hline Clinical characteristics & Point value \\
\hline Clinical signs of DVT & 1 \\
Heart rate $>100$ beats/min & 1 \\
Recent surgery/immobilization & 1 \\
Hemoptysis & 1 \\
Previous PE/DVT & 1 \\
Cancer & 1 \\
Alternative diagnosis less likely & 1
\end{tabular}

DVT Deep vein thrombosis; PE Pulmonary embolism 


\section{APPENDIX TABLE 4}

\section{Modified Wells score}

\begin{tabular}{lc}
\hline Clinical characteristics & Point value \\
\hline Clinical signs of DVT & 3 \\
Heart rate $>100$ beats/min & 1.5 \\
Recent surgery/immobilization & 1.5 \\
Previous PE/DVT & 1.5 \\
Hemoptysis & 1 \\
Active cancer & 1 \\
Alternative diagnosis less likely & 3 \\
$\geq 4$ PE likely & \\
<4 PE unlikely &
\end{tabular}

DVT Deep vein thrombosis; PE Pulmonary embolism

\section{REFERENCES}

1. Geerts WH, Bergqvist D, Pineo GF, et al. Prevention of venous thromboembolism. ACCP Evidence Based Practice Guidelines. Eighth Edition. Chest 2008;133:381-453.

2. Barritt DW, Jordan SC. Anticoagulant drugs in the treatment of pulmonary embolism: A controlled trial. Lancet 1960;i:1309-12.

3. Douketis JD, Foster GA, Crowther MA, et al. Clinical risk factors and timing of recurrent venous thromboembolism during the initial 3 months of anticoagulant therapy. Arch Intern Med 2000;160:3431-6.

4. Karwinski B, Svendsen E. Comparison of clinical and postmortem diagnosis of pulmonary embolism. J Clin Pathol 1989;42:135-9.

5. Roosen J, Frans E, Wilmer A, et al. Comparison of premortem clinical diagnoses in critically ill patients and subsequent autopsy findings. Mayo Clin Proc 2000;75:562-7.

6. Twigg SJ, McCrirrick A, Sanderson PM. A comparison of post mortem findings with post hoc estimated clinical diagnoses of patients who die in a United Kingdom intensive care unit. Intens Care Med 2000;27:706-10.

7. Anderson FA, Wheeler B, Goldberg RJ, et al. A population-based perspective of the hospital incidence and case-fatality rates of deep vein thrombosis and pulmonary embolism. The Worcester DVT Study. Arch Internal Med 1991;151:933-8.

8. Cook D, Crowther M, Meade M, et al. Deep venous thrombosis in medical-surgical critically ill patients: Prevalence, incidence and risk factors. Crit Care Med 2005; 33:1565-71.

9. Subramaniam RM, Mandrekar J, Balir D, et al. The Geneva prognostic score and mortality in patients diagnosed with pulmonary embolism by CT pulmonary angiogram. J Med Imag Rad Onc 2009; 53:361-5.

10. Wells PS, Anderson DR, Bormanis J, et al. Value of assessment of pretest probability of deep-vein thrombosis in clinical management. Lancet 1997;350:1795-8.
11. Wicki J, Perrier A, Perneger TV, et al. Predicting adverse outcomes in patients with acute pulmonary embolism: A risk score. Thromb Haemost 2000;84:548-52.

12. Douma RA, Gibson NS, Gerdes VEA, et al. Validity and clinical utility of the simplified wells rule for assessing clinical probability for the exclusion of pulmonary embolism. Thromb Haemost 2009;101:197-200.

13. Bahia A, Albert RK. The Modified Wells Score accurately excludes pulmonary embolism in hospitalized inpatients receiving heparin prophylaxis. J Hospital Med 2011;6:190-4.

14. Stein PD, Matta F, Musani MH, et al. Silent pulmonary embolism in patients with deep venous thrombosis: A systematic review. Am J Med 2010;123:426-31.

15. The PROTECT Investigators for the Canadian Critical Care Trials Group and the Australian and New Zealand Intensive Care Society Clinical Trials Group: Dalteparin versus unfractionated heparin in critically ill patients. N Engl J Med 2011;364:1305-14.

16. Kucher N, Tapson VF, Goldhaber SZ for the DVT Free Steering Committee. Risk factors associated with symptomatic pulmonary embolism in a large cohort of deep vein thrombosis patients. Thromb Haemost 2005;93:494-8.

17. Fleiss JL. Measuring nominal scale agreement among many raters. Psych Bull 1971;76:378-82.

18. Stengel D, Bauwens K, Walter M, et al. Comparison of handheld computer-assisted and conventional paper chart documentation of medical records. A randomized, controlled trial. J Bone Joint Surg Am 2004;86-A:553-60.

19. Gravely-Witte S, Stewart DE, Suskin N, et al. Cardiologists' charting varied by risk factor, and was often discordant with patient report. J Clin Epidemiol 2008;61:1073-9.

20. Pourasghar F, Malekafzali $\mathrm{H}$, Koch $\mathrm{S}$ et al. Factors influencing the quality of medical documentation when a paper-based medical records system is replaced with an electronic medical records system: An Iranian case study. Int J Technol Assess Health Care 2008;24:445-51.

21. Moran MT, Wiser TH, Nanda J, et al. Measuring medical residents' chart-documentation practices. J Med Educ 2008;63:859-65.

22. Carroll AE, Tarczy-Hornoch P, O'Reilly E, et al. Resident documentation discrepancies in a neonatal intensive care unit. Pediatrics 2003;111:976-80.

23. Siegler EL. The evolving medical record. Ann Intern Med 2010;153:671-7.

24. Minet C, Lugosi M, Savoye Y, et al. Pulmonary embolism in mechanically ventilated patients requiring computed tomography: Prevalence, risk factors and outcome. Crit Care Med 2012;40:3202-8.

25. Becattini C, Vedovati MC, Agnelli G. Prognostic value of troponins in acute pulmonary embolism: A meta-analysis. Circulation 2007;116:427-33.

26. Coutance G, Cauderlier E, Ehtisham J, et al. The prognostic value of markers of right ventricular dysfunction in pulmonary embolism: A meta-analysis. Crit Care 2011;15:R103. 


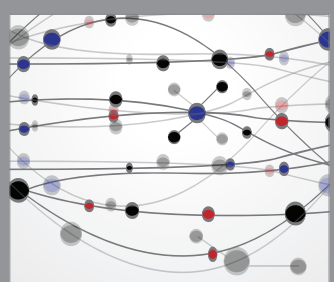

The Scientific World Journal
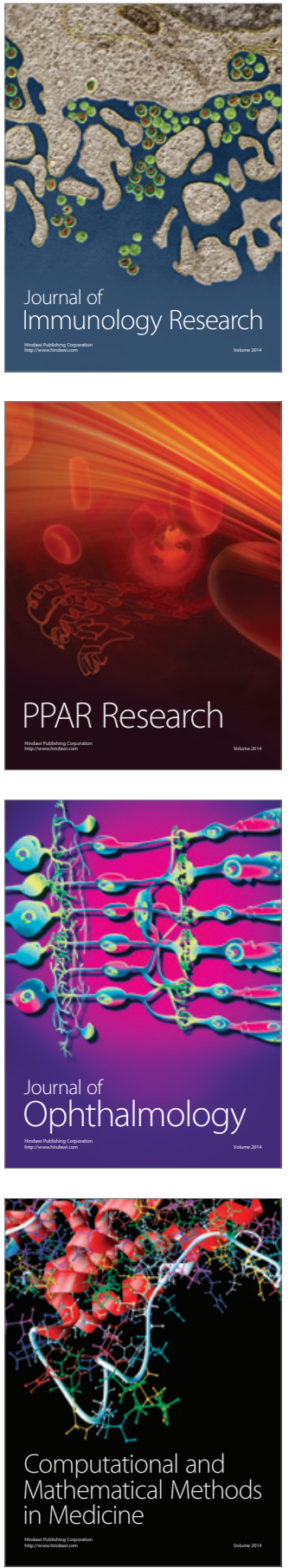

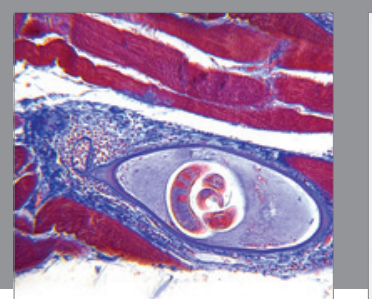

Gastroenterology Research and Practice

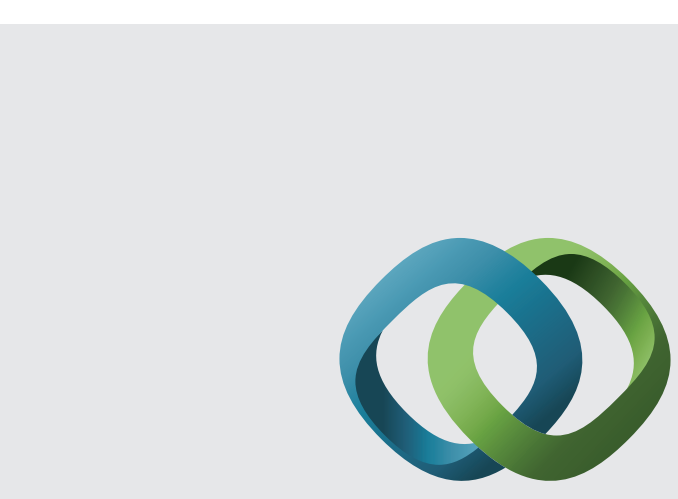

\section{Hindawi}

Submit your manuscripts at

http://www.hindawi.com
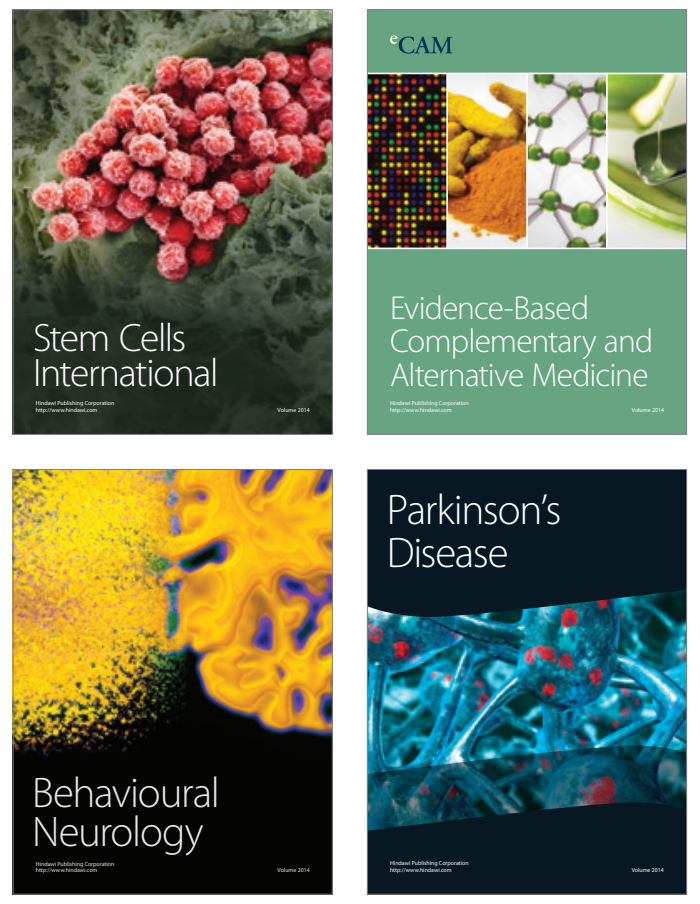
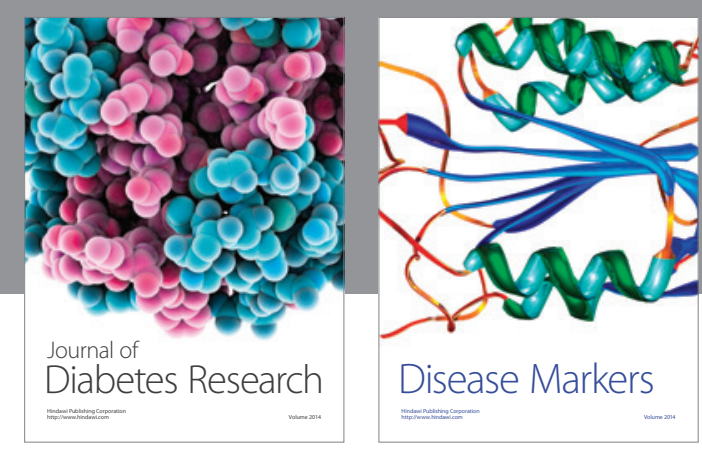

Disease Markers
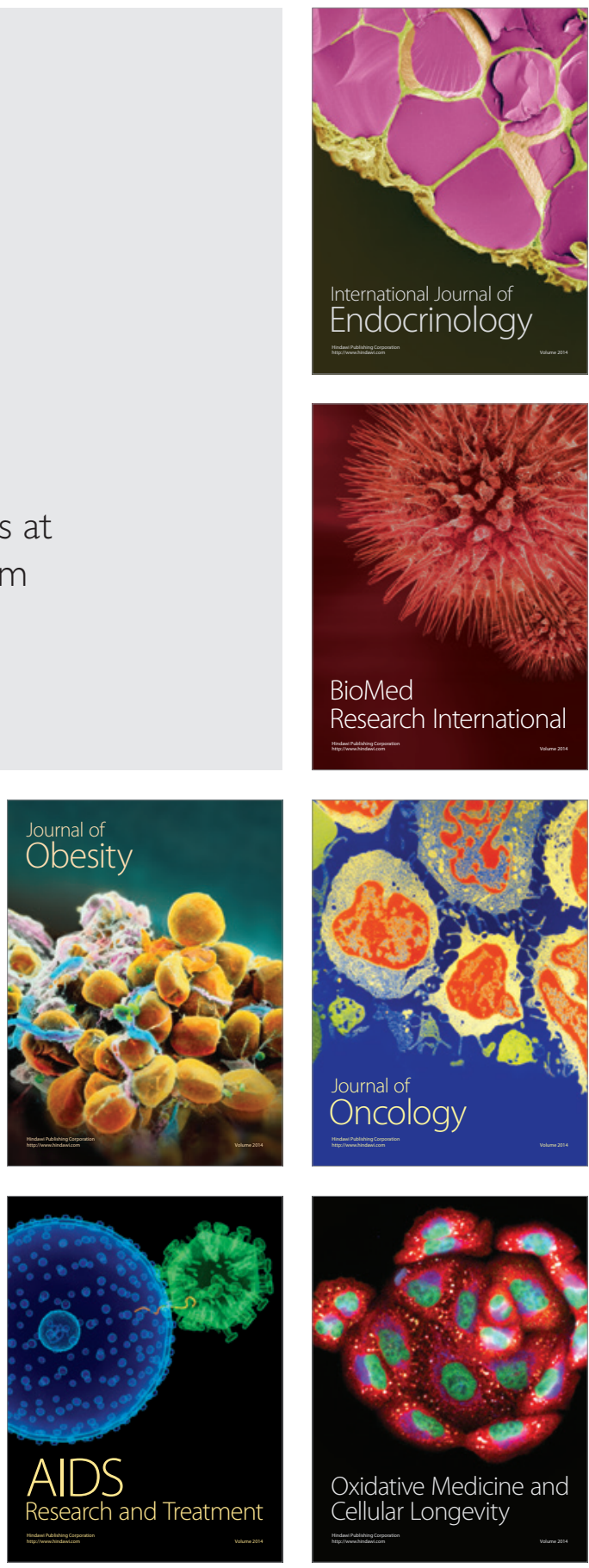